\title{
Qachwa: Riqueza Cultural de Angaraes - Huancavelica
}

\author{
Qachwa: Cultural wealth of Angaraes - Huancavelica \\ Jesús Guillermo Caso Álvarez 1 (D) (8), Antonio Ñahuincopa Arango2 (iD (:8), \\ Ricardo Arango Olarte ${ }^{3}$ (DD (8:)
}

\section{Cómo citar}

Caso Álvarez, J. G., Ñahuincopa Arango, A. y Arango Olarte, R. (2021). Qachwa: riqueza Cultural de Angaraes - Huancavelica. Socialium, 5(2), 282-296. https://doi.org/10.26490/uncp.sl.2021.5.2.936

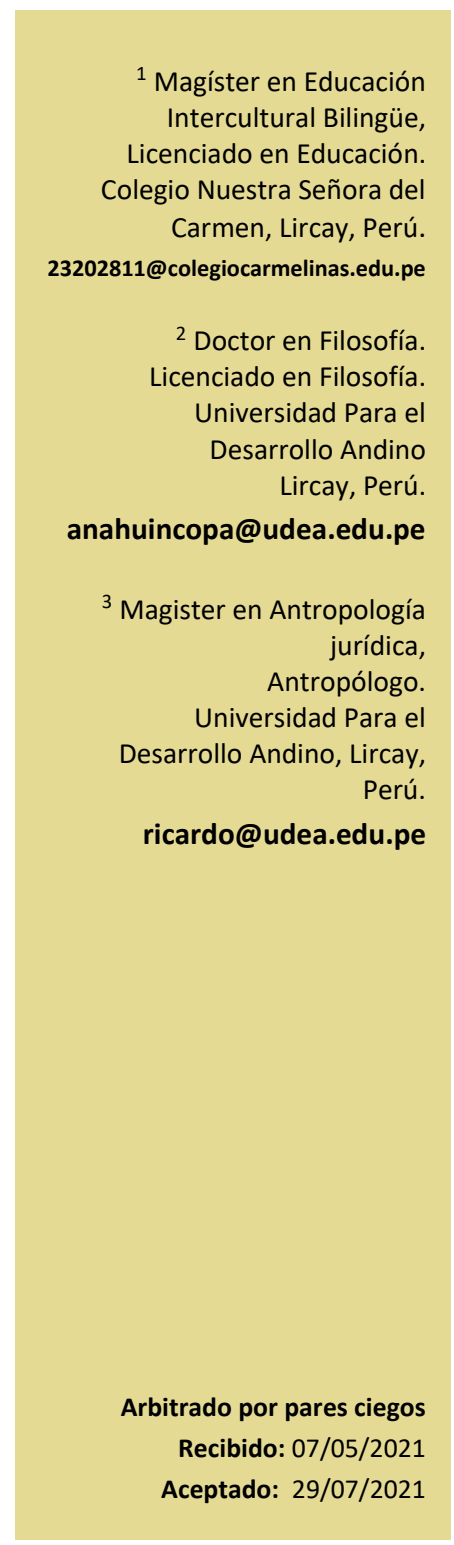

\section{RESUMEN}

Una de las especies líricas de origen quechua se denomina Qachwa, que en castellano sería danza, música y canto de proveniencia ancestral y que perdura en Huancavelica hasta la actualidad. Asimismo, la identidad cultural del poblador huancavelicano es muy arraigada cuya preservación es de mayor importancia. Entonces, es atinado afirmar que, si esta especie se mantuvo incólume, es gracias a la inquebrantable identidad cultural tan fervientemente mantenida. En el presente trabajo de investigación se ha indagado sobre la relación que existe entre la variable Qachwa: Patrimonio Cultural Inmaterial en la Identidad cultural en Huancavelica. El objetivo seguido fue demostrar de qué manera el Qachwa como patrimonio inmaterial se relaciona con la identidad cultural en Huancavelica. En cuanto metodológico, es de tipo básica, con método descriptivo y diseño correlacional, con un muestreo probabilístico. El resultado fue sorprendente, conforme a la aplicación de una encuesta de tipo Likert. El $58 \%$ de encuestados referenciaron que Qachwa es su patrimonio inmaterial, por ello, el $56 \%$ de ellos están de acuerdo en mantener su identidad cultural. En consecuencia, cuanto más se considera que la Qachwa constituye un preciado patrimonio inmaterial, la identidad cultural de los huancavelicanos se consolida para preservar y conservar su mencionada identidad.

Palabras clave: patrimonio cultural; danza; música; identidad cultural.

\section{ABSTRACT}

One of the lyrical species of Quechua origin is called Qachwa, which in Castilian would be dance, music and song of ancestral origin and that lasts in Huancavelica until today. Likewise, the cultural identity of the huancavelicano settlers is deeply rooted, whose preservation is of the greatest importance. So, it is correct to say that, if this species remained unscathed, it is thanks to the unbreakable cultural identity so fervently maintained. In this research work, the relationship that exists between the variable Qachwa: Intangible Cultural Heritage and cultural Identity in Huancavelica has been investigated. The objective followed was to demonstrate how the Qachwa as intangible heritage is related to the cultural identity in Huancavelica. As regards methodological, it is of a basic type, with a descriptive method and correlational design, with a probability sampling. The result was surprising, according to the application of a Likert-type survey. 58\% of respondents mentioned that Qachwa is their intangible heritage, therefore, $56 \%$ of them agree to maintain their cultural identity. Consequently, the more the Qachwa is considered to be a precious intangible heritage, the cultural identity of the Huancavelicans is consolidated to preserve and conserve their aforementioned identity.

Keywords: cultural heritage; dance; music; cultural identity. 


\section{Introducción}

La Qachwa es una especie musical de la lírica quechua. Su armonía, compás y tono es de dos formas, uno de tono lento y pausado que se conoce como Kashua Triste, Ilaki qachwa dedicada al amor, la vida, la naturaleza, los animales, practicado generalmente por gente adulta. La Kashua alegre y jocosa kusi qachwa cuya tonalidad, compás y armonía son rápidos y dinámicos. Esta última, es practicada mayormente por la juventud. En efecto, aquí se deja fluir el sentimiento, la expresividad y la voluptuosidad de la energía juvenil.

Esta especie tiene alcance a la danza, música, canto y poesía.

Tanto el mensaje como el contenido de esta qachwa toca al corazón, es el testimonio de entrega a la amada y la falta que hace cuando el amor termina, un cuarteto de pie quebrado, dijera Jorge Manrique. Es una vivencia, es la vida misma. La música qachwa, compasada y viril, invita salir raudamente a las lágrimas de pura alegría. (Caso y Yauri, 2009, p. 9)

\section{Kashua triste}

Tuyaschallay Tuyaschallay

Chukra umacha tuyaschallay

Chukra umacha kallaspachu

Waqachisaqmi niwarqanki

Ay llakichisaqmi niwarqanki

Niwarqanki

Kullkuchallay kullkuchallay

Puka ñawicha kullkuchallay

Puka ñawicha kallaspachu

Waqachisaqmi niwarqanki

Ay llakichisaqmi niwarqanki

Niwarqanki
Calandria, calandria

Tienes copete calandria

Porque tienes copete

Dijiste que me harías llorar

Dijiste que me harías sufrir

Me dijiste

Tortolita, tortolita

Tienes ojos rojos tortolita

Porque tienes ojos rojos

Dijiste que me harías llorar

Dijiste que me harías sufrir

Me dijiste 


$\begin{array}{ll}\text { Kashua alegre } & \\ \text { Kutichikuy, kutichikuy } & \text { Devuélvete, devuélvete } \\ \text { Warmi } & \text { Mujer } \\ \text { Kutichikuy kutichikuy } & \text { Devuélvete, devuélvete } \\ \text { champa uma wawaykita } & \text { Tu hijo cabeza de césped } \\ \text { kutichikuy kutichikuy } & \text { Devuélvete, devuélvete } \\ \text { chasara uma wawaykita } & \text { Tu hijo cabello desordenado } \\ \text { manaña manaña munallanichu } & \text { Ya no, ya no, ya no lo quiero } \\ \text { lapsu siki wawaykita } & \text { Tu hijo pantalón holgado } \\ \text { manana manaña munallanichu } & \text { Ya no, ya no, ya no lo quiero } \\ \text { weqa siki wawaykita } & \text { Tu hijo pantalón caído } \\ \text { wawaykita } & \text { A tu hijo } \\ \text { (Caso y Yauri, 2009, p. 9) }\end{array}$

\section{Música huancavelicana}

Constituye una gama de tonos y voces que remontan al pasado esplendor de esta tierra. Hasta el momento ha perdurado su presencia como una auténtica expresión más rica y de variada melodía. La música huancavelicana está asentada en el género lírico cuyas especies son tan vivas y actuales a pesar de provenir desde la época precolonial. Las especies que aún tienen vigencia en el territorio huancavelicano son: Cashua, Huayno (Gutiérrez, 2019, p. 15). El Haylli, Harahui, carnaval y Santiago que detallamos líneas arriba.

En cada una de estas especies entonadas, interpretadas y vocalizadas; como aglutinación de tonadas son también parte de las danzas.

\section{Danzas huancavelicanas}

Este género agrupa a las diferentes especies líricas del quechua que es una manifestación ancestral practicada de generación en generación.

Las danzas que tuvieron presencia en este trabajo fue Pacha Walay (amanecer) que es una danza de romance o idilio, practicado por jóvenes casamenteros en contextos de fiestas patronales o en las estancias solitarias con funciones de cuidado de ganado. Kapuli Pallay (cosecha de guindas) es una danza 
de faena en la modalidad de peón, minka. Consiste en recoger o cosechar los frutos del árbol de la guinda, kapuli con un arpón, simpi utilizado por los cosechadores o qayay minka. Tanto la danza de amor como la de faena representan las costumbres y tradiciones tan peculiares de esta tierra prometedora, siempre practicando los más altos acervos y/o patrimonios culturales.

\section{La bandurria}

La bandurria huancavelicana, es un instrumento musical pentafónico generalizada, consta de un mástil corto, clavijero de 12 a 16 cuerdas. Las cuerdas se enganchan desde la cuarta parte de la base de la caja. La caja es en forma de pera de base ancha. En Huancavelica se toca con las uñas del dedo pulgar y el índice en forma de pizzicato, es decir, pellizcando las cuerdas con las uñas. La afinación está estructurada de la siguiente manera: Las primeras tres cuerdas del bloque 1, es nota $\mathrm{Ml}$, las tres cuerdas del segundo bloque es $\mathrm{SI}$, las dos primeras cuerdas del tercer bloque es FA y la tercera cuerda del tercer bloque es SOL. Pasando al cuarto y último bloque, las tres son la nota RE.

En el Perú, sólo tres departamentos fueron afortunados como habilidosos para adecuar el laúd o la mandola occidental a la bandurria andina.

Cusco obtuvo el kanchis y marimachu con los que revolucionaron su qashua como el caso de Pedro Corrales de Canas y conjunto Santa Bárbara de Canchis. En esta especie prepondera el rasgado y el pizzicato en menor escala.

En Ayacucho, el chimaycha y el pumpin son ejecutados magistralmente con la diminuta bandurria andina Ilamada chinlili.

En Huancavelica, la qachwa se ejecuta con la bandurria andina que es de dos tipos: La bandurria contralto llamada chintu y la bandurria pequeña soprano denominada chinlicha (Caso, 2020, p. 23).

\section{Patrimonio cultural inmaterial}

Constituye la infinidad de hechos, conductas y actividades como bagaje y legado de nuestros antepasados. Este capital cultural, como la costumbre popular tradicional de nuestros pueblos, ha sido transmitido de una generación anterior a la actual con proyección al futuro. El patrimonio inmaterial o intangible constituye la música, la danza, las costumbres tradicionales, fiestas patronales, faenas comunales, comida típica, artesanía, literatura de tradición oral y tantos otros que en la actualidad pervive como expresión sui genérica en cada uno de nuestros pueblos (González, 2016, pp. 13-14). En estos tiempos se necesita promover una política social, para desde allí ver un mundo competitivo y que esto trasciende en la memoria colectiva (Arizpe, 2006, p. 13).

En concreto, el vasto conocimiento o el saber previo tan amplio de la comunidad, constituyen una rica y abundante herencia de muchos siglos y resguardado con tanto celo adquirido y practicado por los abuelos, 
que luego transmitido a las generaciones posteriores. Gracias a ese interés generoso de la población, ahora podemos contar con un sinnúmero de manifestaciones muy variadas y útiles que componen el patrimonio cultural e inmaterial. Por ello, el rescate, preservación, conservación y difusión de nuestro legado cultural es un deber irrenunciable, vital e importante. Todos obtuvimos una serie de tenencias de corte cultural y tenemos la obligación de legar a nuestros descendientes.

\section{La lírica como patrimonio cultural inmaterial}

La manifestación de canto, música, danza y poesía desde nuestros ancestros constituye el acervo más rico y más propio de cada pueblo andino. La tradición registrada oralmente de generación en generación se evidencia con la patente existencia de estas manifestaciones de sentimiento y pasión.

Las canciones y la música se cultivaron en el pasado netamente de forma oral con una fortificada duración hasta estos tiempos. Como la conservación fue leal, de hecho, pervivirá en el futuro con bastante arraigo. Las especies que aún tienen subsistencia y su desempeño es vivencial en Huancavelica, podemos catalogar en lo siguiente: la qachwa, motivo amoroso de la juventud; el qarawi, con funciones de unión, trabajo y en algunas veces, culto a la divinidad; el qaylli, con motivos de alegría, dicha y bullicio; el waynu como manifestación social en masa (Tito, 2005, p. 19).

También tenemos el tamborilear o tocar el atabal a los animales: uywa tinyay, conocido como santiago, consiste en poner las cintas de colores en la oreja de los animales: achalachiy o tukillachiy. Finalmente, el carnaval (Carnevalerum: Culto al dios Baco) en los andes denominado pukllay con motivos de rendir pleitesía a la tierra por los grandes frutos cosechados con bastante éxito (Porras, 1999, p. 41).

Las diferentes canciones que recapitula la vasta música huancavelicana confluyen en la lírica andina, cuya característica no tiene comparación con las occidentales. La música es un enlace perfecto para la cohesión social en el mundo andino. Es el lenguaje y arte universal de entendimiento y concordancia. Por esta razón, hasta este momento, encontramos una armonía sin igual de la filarmonía en la voz de los intérpretes. La palabra hilvanada, con carga afectiva fielmente andinas, ornamentada con figuras literarias quechuas, la armonía variada y repleta de sentimiento, pasión y afectividad dan cuenta de la gran herencia lírica de nuestra música.

Las manifestaciones presentadas tienen un soporte incalculable que es el idioma quechua, increíblemente el canto en quechua y viceversa, admirablemente cada pronunciación y articulación de los sonidos del habla y lengua tienen una armonía, es dulce y apacible que invita a bailar y cantar (Morales, 2012, p. 48). De igual modo, abundan las circunstancias de humor y alegría, pero, por otro lado, la tristeza como en toda sociedad, sin que falte, por consiguiente, la ironía y la parodia (Maldonado, 2017, p. 58). 
En el análisis desleal sobre la lírica quechua aseguraron que estaba repleta de melancolía y aflicción, había cierta tristeza permanente, como si la población tuviera una vida doliente, pero no es cierto, las manifestaciones líricas de la actualidad desvirtúan esas afirmaciones

Es falso que la desolación, la pobreza y la orfandad material haya sido parte del poblador oriundo peruano. Al contrario, tuvieron una vida de regocijo ya que no conocieron la pobreza material, no existe la equivalencia quechua de "la pobreza" ni de "maldad"; solo encontramos levemente la palabra usuq para "pobre" y lo contrario de bien (allin kausay) para el mal (mana allin) que no es exactamente el significado de las palabras "pobre" ni "mal".

Nuestros antepasados cantaban, bailaban y ejecutaban instrumentos musicales de los más extraordinarios. En plena época colonial, muchos instrumentos musicales occidentales fueron magistralmente andinizados.

\section{Identidad}

La pregunta de cualquier individuo con respecto a la pertenencia sería, ¿En qué grupo no estoy? 0 ¿En qué grupo falto yo?

La respuesta a estas interrogantes se encontraría definiendo y buscando a cuál de los grupos pertenece uno. Para ello se debe identificar los rasgos más comunes y las concepciones del mundo, las costumbres, las tradiciones, las conductas y actitudes que deben coincidir con un grupo determinado, de esa manera encontrará en qué grupo está faltando. Respondiendo a la pregunta, sabe en qué grupo no está y sabe también en qué grupo está siendo falta.

Como ejemplo podemos recurrir a un caso concreto: Un quechua hablante, con actitudes de masticar coca y conductas de clamar a la mama pacha, con costumbres de madrugar para sembrar o cosechar, con tradiciones de mantener las fiestas costumbristas jamás podrá hacer falta en el distrito más urbano de la sociedad limeña, pues, nuestro personaje pertenece a unos de los coloridos pueblecitos de nuestro ande peruano. Un lema de algún intelectual contemporáneo dice: "Una persona tiene derecho a conocer su pasado para defender su identidad".

Entonces, La identidad es la búsqueda de sí mismo, saber quién es en verdad y a dónde pertenece, al hallar ese rasgo llega a la conciencia de reconocerse como diferente a los demás. Todo eso se puede lograr conforme la sociedad lo influencie para pertenecer a un grupo, pero teniendo presente su yo existencial. El hombre siempre, "busca su identidad", "se autodefine" y su palabra es muy emotiva: "soy lo que soy", "somos lo que somos", "nadie como yo", "yo soy único y no me parezco a ninguno" (Segura, 2014, p. 18). 


\section{Cultura}

El término cultura, es en realidad polisémica, pues tiene muchos significados. Referente a este trabajo se podría conceptuarse como una aglomeración ordenada de heredades materiales e inmateriales conocidos también, este último, como espirituales que se transmite de abuelos a nietos y que los hereditarios están obligados a mantener por hábitos descendenciales para seguir practicando individual o colectivamente. Con respecto a la cultura, Molano (2007) dice:

Aunque existen diversas definiciones, en general, todas coinciden en que cultura es lo que le da vida al ser humano: sus tradiciones, costumbres, fiestas, conocimiento, creencias, moral. Se podría decir que la cultura tiene varias dimensiones y funciones sociales, que generan: a. un modo de vivir, b. cohesión social, c. creación de riqueza y empleo, d. equilibrio territorial [sic]. (p. 72)

La cultura está precedida por la palabra civilización que expresa el orden político en que se desempeña y se desenvuelve. La cortesía con los demás, el deber cívico y los derechos que le conceden, le ubica al ser en la civilidad, pues esa cualidad le aleja del salvajismo y de hecho también de la barbarie. Hoy en día se habla de persona culta (cultivada) e ignorante (sin cultivar) para referirse a los que viven en el pasado o en la actualidad y conforme a las normas civiles.

\section{Identidad cultural}

Cualquier grupo social de cualquier época vive en sociedad, es decir, formando un grupo que constituyen individuos de rasgos comunes y que por naturaleza familiar y cultural se unieron. Por supuesto que la sociedad lo acoge de manera incondicional y automática (Mena, 1991, p. 88).

Para que en este grupo se desenvuelva cómodamente en sociedad y en interrelación con los demás, debe haber algo que les une y les haga pensar en común. Precisamente, existe un elemento que cohesiona, actitudes y conductas comunes. Este agente cohesionador se da mediante sus costumbres, tradiciones, creencias, supersticiones, valores y las diversas formas de comportamiento. A todo lo que acabamos de mencionar se les llama identidades culturales (Espinoza, 2011, p. 66).

\section{Definición endógena (mismidad)}

Es el momento en que desarrollamos una conciencia real, empezamos a definirnos también a nosotros mismos, a desarrollar el concepto de nosotros mismos, como se dice, desde nuestra situación interna, endógena, por lo tanto, desarrollamos una identidad. Mismidad, corresponde pues a la autodefinición de su individualidad, de su existencia independiente de un rasgo exterior. 


\section{Definición exógena (otredad)}

Una definición venida de fuera, un reconocimiento externo, aceptando lo que realmente uno es para el otro. La otredad afirma la existencia de la mismidad, complementándose entre ambas. Esta cita puede aclarar el concepto.

Hay una relación con el hundimiento que no es solamente entre el ser y la nada, entre el yo y el otro, porque lo más inquietante no acontece ni en el yo ni en el otro, ni en el ser ni en la nada, sino en el medio, en el "entre" uno y otro. Efectivamente, para componer algo es necesaria la existencia de este "tercero" que lo constituye, que lo inviste. Lo mismo, 'lo otro'... y lo que va 'en medio'. Parece cierto eso de que "no hay dos sin tres" y que entre la mismidad y la otredad hay que pensar en esos terceros. (Kaminsky, 2014, p. 33)

Ninguna persona podría vivir ni desenvolverse en su medio sin la influencia ni compañía del otro, el uno necesita del otro para ser efectivamente lo que es uno, por lo tanto, el uno y el otro son como las dos caras de una moneda que no podría existir sin esa unidad doble.

\section{Características de identidad cultural}

Las diversas actividades en razón de dar fortalecimiento a una comunidad, los acuerdos y normas de convivencia de los integrantes del grupo. Las diferencias, discordias y hasta enfrentamientos son heredades comunales o sociales que caracterizan a la identidad cultural.

De hecho, la identidad cobra importancia porque presenta la infinidad de hechos y acciones de convivencia y aceptación, por ello, su relación con otras categorías es inminente, la política como toma de decisión es parte, la cuestión social no rechaza siendo constituyente básico y el tema económico necesita de la cultura para mejorar su estabilidad (Hargreaves, 1996, pp. 40-41).

Como corresponde, también las teorías en que se basa la identidad cultural serán necesarias en este artículo.

\section{Teoría que evidencia el patrimonio inmaterial}

Es de mucho valor acudir a las teorías psicopedagógicas que abundan dentro de la pedagogía y la didáctica. Es un deber y una responsabilidad contar con estas teorías que puedan corroborar la certeza y la evidencia de que pueda existir una correlación con alguna otra disciplina como es el caso de identidad cultural en este trabajo en particular. A continuación, se mencionan algunas teorías con respecto a la Qachwa, patrimonio inmaterial.

Teoría cultural unilateral o del evolucionismo de Taylor. Las culturas evolucionan desde las más antiguas simples hasta las contemporáneas que son muy complejas. En todo caso, desde el salvajismo ha pervivido 
las actividades de caza, pesca y recolección de frutos hasta llegar a la barbarie donde ya existe cierta forma de agricultura, la utilización de instrumentos de metal y por supuesto, la instauración de la escritura (Fonseca, 1992, p. 30).

De esta forma ha ido adquiriendo los bienes que constituyen el patrimonio, la caza, la pesca como costumbres que forman parte de su herencia inmaterial para la humanidad.

\section{Teoría de identidad cultural}

Teoría culturalista de Hoggart, Williams y Thompson. La teoría cultural entiende a la comunicación como un saber compartido entre un conjunto de individuos que pertenecen a un determinado contexto. Dichos individuos utilizan el mismo código para entenderse entre sí. Este código viene dado por la cultura de cada individuo y se mantendrá año tras año marcando las costumbres, ideologías y tradiciones que dentro de ese contexto serán vistas como "lo normal". Mientras que las demás culturas, por el contrario, serán vistas como "lo extraño y ajeno" (Basáez, 2019, p. 45). Por ello, es necesaria una comunicación intercultural definida como el manejo de mensajes con el fin de crear el significado a través de culturas. Con esto encontraríamos diversidad de opiniones que generaría una riqueza cultural inmensa que acreciente el caudal del patrimonio inmaterial. Richard Hoggart, Raymond Williams y Edward P. Thompson son los representantes de esta teoría.

Teoría de Desarrollo de la Identidad de Arthur Chickering y Linda Reisser (1993). Los precursores de esta teoría han propuesto un conjunto de procesos con respecto a la mejora gradual de la identidad. Para ello establecieron una serie de estadíos que desde la óptica de desarrollo pueda abarcar a espacios plenos de alcanzar una verdadera identidad.

Entre estos vectores, que así denominaron los teóricos, tenemos: Se debe desarrollar las diferentes competencias como las físicas y las intelectuales de la persona para tener plena conciencia de la identidad. La persona debe saber manejar sus emociones en el sentido de controlar, aceptar o reconocer. El hombre debe procurar la adquisición de la autosuficiencia para no sucumbir por la falta aparente de todo (Carrillo, 2013, p. 18). Fortificarse en la intrapersonal, es decir, debe alcanzar una madurez suficiente para relacionarse con suficiencia en la relación con sus demás. En tal sentido, debe practicar normas de convivencia regulado por la buena comunicación, la confianza y la impecable honestidad.

Asimismo, debe instaurar su verdadera identidad, sin incitar su ego ni desperdigando en su yo en donde caiga. Saber reconocer quién es quién y quiénes son los que son, es importante. El propósito que persigue la persona es vital, plantearse interrogantes como ¿quién es?, ¿quién va a llegar a ser? Marcarán un referente para alcanzar sus metas y vencer algunos obstáculos en el camino. Finalmente, cuidar su 
integridad, desarrollarse como persona dentro del civismo y lealtad, asumiendo compromisos que le competen dentro de la sociedad y beneficiándose de los derechos que le permitan vivir con identidad.

\section{Método}

Tipo y diseño de investigación. La presente investigación es de tipo básica, porque estuvo orientada en establecer la relación entre patrimonio inmaterial Qachwa e identidad cultural, en el marco del enfoque cuantitativo. Nivel descriptivo, porque está orientada al conocimiento de la realidad tal como se presenta en una situación espacio-temporal dada. El diseño es correlacional, que consiste en describir, analizar e interpretar sistemáticamente un conjunto de hechos o fenómenos y las variables que los caracterizan de manera tal y como se dan en el presente (Sánchez y Reyes, 2009)

Población y muestra. La población considerada para el estudio estuvo conformada por un total de 8,060 pobladores mayores de 18 años, quienes conocen y practican la danza de la Qachwa. El muestreo fue probabilístico, dado que nos basamos en el principio de equiprobabilidad, es decir que todos los pobladores tuvieron la misma probabilidad de ser elegidos para formar parte de la muestra representativa de la población, la muestra seleccionada para la investigación estuvo compuesta por un total de 376 pobladores.

Instrumentos de recolección de datos. Se hizo uso de la técnica de escalamiento y el instrumento de cuestionario de Escala de Likert, con la escala de: 1 totalmente de acuerdo, 2 de acuerdo, 3 ni en acuerdo ni en desacuerdo, 4 en desacuerdo y 5 totalmente en desacuerdo, que fue validado por la modalidad de juicio de expertos. Se utilizó el muestreo probabilístico aleatorio simple.

Procedimientos de la recolección de datos. La técnica utilizada fue la encuesta y el instrumento fue el cuestionario elaborada según la Escala de Likert, la cual se aplicó a la muestra seleccionada en todo el ámbito de la capital provincial de Angaraes, compuesta por un total de 152 mujeres y 215 varones.

Aspectos éticos. Los participantes voluntariamente mostraron su acuerdo para formar parte de la investigación antes de iniciar el rellenado del cuestionario, para el cual fue necesario explicarles que sus respuestas eran absolutamente anónimas en consecuencia, se empezó a contestar las preguntas libremente.

Análisis de datos. El procesamiento estadístico se ha ejecutado utilizando el programa SPSS 25 , en la cual se generó una base de datos, reportando tablas, con frecuencias, porcentajes y correlación, las que fueron analizadas y demostradas con el apoyo del estadístico T de Student. 


\section{Resultado}

La investigación se sustenta en los resultados estadísticos muy considerables que se ha sometido a la estadística descriptiva. La encuesta se aplicó a la muestra de 376 pobladores y procesada por el software SPSS 25.0, teniendo los siguientes datos:

Tabla 1

Patrimonio Inmaterial

\begin{tabular}{lcc}
\hline & Patrimonio Inmaterial & Número \\
\hline Totalmente de acuerdo & $58 \%$ & 218 \\
De acuerdo & $31 \%$ & 117 \\
Ni de acuerdo ni en desacuerdo & $8 \%$ & 30 \\
Totalmente en desacuerdo & $2 \%$ & 7 \\
Totalmente en desacuerdo & $1 \%$ & 4 \\
Total & $100 \%$ & 376 \\
\hline
\end{tabular}

$\overline{\text { Nota. Tomado de la información recogida de la encuesta en la provincia de Angaraes - Huancavelica - } 2020 .}$

Aquí se aprecia que el $58 \%$ de los encuestados está totalmente de acuerdo en considerar que la Qachwa es patrimonio inmaterial y solo el $1 \%$ totalmente en desacuerdo de que Qachwa fuera patrimonio inmaterial.

Tabla 2

Identidad cultural

\begin{tabular}{|c|c|c|}
\hline & Identidad cultural & Número \\
\hline Totalmente de acuerdo & $56 \%$ & 210 \\
\hline De acuerdo & $32 \%$ & 120 \\
\hline $\begin{array}{l}\text { Ni de acuerdo ni en } \\
\text { desacuerdo }\end{array}$ & $8 \%$ & 30 \\
\hline $\begin{array}{l}\text { Totalmente en } \\
\text { desacuerdo }\end{array}$ & $2 \%$ & 8 \\
\hline $\begin{array}{l}\text { Totalmente en } \\
\text { desacuerdo }\end{array}$ & $2 \%$ & 8 \\
\hline Total & $100 \%$ & 376 \\
\hline
\end{tabular}

Asimismo, se puede ver que el $56 \%$ de los encuestados referencian estar totalmente de acuerdo en mantener su identidad cultural, solo el $2 \%$ manifiestan estar totalmente en desacuerdo de mantener su identidad cultural. 


\section{Tabla 3}

Coeficiente de correlación patrimonio inmaterial e identidad cultural

\begin{tabular}{|c|c|c|c|c|}
\hline & & $\begin{array}{l}\text { Patrimonio } \\
\text { inmaterial }\end{array}$ & $\begin{array}{l}\text { Identidad } \\
\text { cultural }\end{array}$ & $\begin{array}{c}\text { Nivel de } \\
\text { significación }\end{array}$ \\
\hline \multirow{3}{*}{$\begin{array}{l}\text { Patrimonio } \\
\text { inmaterial }\end{array}$} & $\begin{array}{l}\text { Correlación de } \\
\text { Pearson }\end{array}$ & 1 & 0,610 & \multirow{3}{*}{0,05} \\
\hline & Sig. (bilateral) & & 0,000 & \\
\hline & $\mathrm{N}$ & 367 & 367 & \\
\hline \multirow{3}{*}{$\begin{array}{l}\text { Identidad } \\
\text { cultural }\end{array}$} & $\begin{array}{l}\text { Correlación de } \\
\text { Pearson }\end{array}$ & 0,610 & 1 & \multirow{3}{*}{0,05} \\
\hline & Sig. (bilateral) & 0,000 & & \\
\hline & $\mathrm{N}$ & 367 & 367 & \\
\hline
\end{tabular}

Nota. Según la tabla la correlación es significativa al nivel 0,01 (bilateral).

De acuerdo a la tabla mostrada, el coeficiente de correlación de Pearson $r=0,610$. Entonces el grado de correlación entre las variables patrimonio inmaterial e identidad cultural según el cuadro de Sampieri es correlación positiva media, de acuerdo a los índices de correlación.

Este resultado solo es aplicable a la muestra, para determinar si la correlación es significativa se debe realizar la prueba t de Student.

\section{Discusión}

La Qachwa, especie musical andina de Huancavelica, nunca ha sido investigada, por lo tanto, no tendría un antecedente directo, sino de manera indirecta, referenciado o relacionado a trabajos similares.

En ese sentido, se infiere, con un nivel de significación de 0,05; que Qachwa: Patrimonio Inmaterial se relaciona plenamente con la Identidad Cultural conforme a la respuesta de los pobladores.

De acuerdo al resultado obtenido con el SPSS, la correlación de Pearson es $r=0,610$. Existiendo una correlación significativa al nivel 0,01 (bilateral). Además, la prueba t de student es $\mathrm{t}=8,255$ rechaza la Hipótesis Nula (HO: $\rho=0$ ), aceptando la Hipótesis Alterna $(\rho \neq 0)$. Confirmándose que la Qachwa como Patrimonio Inmaterial y la identidad cultural son interrelacionantes.

Los resultados obtenidos son muy similares, en el Perú como país multiétnico está unido en un proyecto nacional, identidad supranacional e identidades étnicas. De modo que es de necesidad abarcar los resultados con otras investigaciones (Espinoza, 2011).

De acuerdo al resultado obtenido con el SPSS, la correlación de Pearson es $r=0,570$. Existiendo una correlación significativa al nivel 0,01 (bilateral). Además, la prueba t de student es t= 7,349 ha rechazado la Hipótesis Nula (HO: $\rho=0)$, y se acepta la Hipótesis Alterna $(\rho \neq 0)$. Ello significa que hay dependencia 
entre las variables, y nuevamente confirma la existencia de la relación entre la Qachwa como Patrimonio Inmaterial música huancavelicana y la identidad cultural.

Los resultados que se han obtenido en este trabajo tienen bastante relación con lo señalado por (Tito, 2005), quien afirma que el huayno, en relación con la qachwa, es una manifestación lírica que tiene como lugar preponderante la zona andina. Asimismo, el huayno representa el sentir y vibrar de los pueblos marginales de Lima, conformado por la mayoría de inmigrantes. La lengua quechua es el complemento de la vigencia del huayno. Esto motiva a entender que este trabajo tiene una base de antecedentes que conlleva a entender que las especies andinas tienen tanto arraigo y relación entre sí.

El nivel significativo de 0,05 , hace inferir que el Patrimonio Inmaterial Danzas huancavelicanas se relaciona significativamente con la Identidad Cultural con los encuestados en la provincia de Angaraes.

De acuerdo al resultado obtenido con el SPSS, la correlación de Pearson es $r=0,414$. Existiendo una correlación significativa al nivel 0,01 (bilateral). Además, la prueba t de student es $t=4,876$ que refuta la Hipótesis Nula (HO: $\rho=0)$, reconociendo la Hipótesis Alterna $(\rho \neq 0)$. Se evidencia la relación que hay entre la Qachwa como Patrimonio Inmaterial danzas Huancavelicanas y la identidad cultural.

Como también menciona (González, 2015), quien afirma que la imagen en el mundo predominante visual es una herramienta indispensable para la comprensión, la protección y la conservación del patrimonio cultural inmaterial. Documentar es salvaguardar el patrimonio inmaterial como un proceso creativo y vivo en continua evolución.

Estas muestras de los antecedentes y los resultados obtenidos con los estadígrafos de la estadística descriptiva e inferencial le dan el carácter científico a este trabajo. Los resultados son muy motivadores para emprender otras investigaciones de carácter social con la única finalidad de poner los resultados y su valía al servicio de la población angareña y como herramienta para la sociedad científica con interés de aportar en sus investigaciones.

\section{Conclusión}

Con un nivel de significación de 0,05; La Qachwa como Patrimonio Cultural Inmaterial se relaciona significativamente con la identidad cultural, constituyendo el conjunto de bienes intangibles de los pueblos de Lircay, Angaraes y Huancavelica.

Con un nivel de significación de 0,05; el Patrimonio Inmaterial Música se relaciona significativamente con la identidad cultural, como heredad patrimonial intangible que tiene directa relación con la Qachwa. 
Con un nivel de significación de 0,05; el Patrimonio Inmaterial Danzas se relaciona significativamente con la identidad cultural como parte inseparable de la música y de hecho por sí misma es la especie musical de la lírica andina conocida como Qachwa.

La qachwa como riqueza cultural está íntimamente relacionada con la identidad cultural, es decir, le permite sentir orgullo de lo suyo y sugiere que debe guardar con celo su patrimonio con la finalidad de rescatar, preservar y difundir.

\section{Referencias}

Arizpe, L. (2006). Los debates internacionales en torno al patrimonio cultural inmaterial. Cuicuilco, 13(38), 13-27. https://www.redalyc.org/pdf/351/35103802.pdf.

Basáez, G., Márquez, F., Rodríguez, T. y Stiglich, C. (2019). Vivencia del desempeño ocupacional de los roles de parentalidad, estudiantes y trabajador (a) al vivirlos simultáneamente [Tesis doctoral, Universidad Andrés Bello]. Repositorio institucional UAB. http://repositorio.unab.cl/xmlui/handle/ria/14591

Carrillo, L. (2013). Conocer los Factores que Intervienen en el Desarrollo de los Siete Vectores de Arthur W. Chickering en el Estudiante Universitario. [Tesis de maestría, Tecnológico de Monterrey]. Repositorio institucional TEC. https://repositorio.tec.mx/handle/11285/619565

Caso, J. (2020). Lírica Quechua de Tradición Oral Autóctona. Municipalidad de Lima. https://www.descubrelima.pe/wp-content/uploads/2020/10/Lirica-Quechua.pdf

Caso, J. y Yauri, V. (2009). Literatura quechua: saberes ancestrales de tradición oral autóctona. Universidad Para el Desarrollo Andino. http://repositorio.udea.edu.pe/handle/123456789/72

Espinoza, A. (2011). Estudios sobre identidad nacional en el Perú y sus correlatos psicológicos, sociales y culturales [Tesis doctoral, Universidad del País Vasco]. Repositorio institucional EHU. https://addi.ehu.es/handle/10810/12206

Fonseca, O. (1992). Historia antigua de Costa Rica: surgimiento y caracterización de la primera civilización costarricense ( $5 \underline{a}$ ed.). Universidad de Costa Rica.

González, S. (2016). La salvaguarda del patrimonio inmaterial en España [Tesis doctoral, Universidad Complutense de Madrid]. Repositorio institucional UCM. https://eprints.ucm.es/id/eprint/38177/1/T37405.pdf

Gutiérrez, T. (2019). El Huayno Ayacuchano en la Identidad Cultural de las Estudiantes de Educación Inicial EIB en el IESPP Nuestra Señora de Lourdes, Ayacucho, 2019 [Tesis doctoral, Universidad Nacional de Educación Enrique Guzmán y Valle]. Repositorio institucional UNE. http://repositorio.une.edu.pe/handle/UNE/4142 
Hargreaves, A. (1996). Profesorado, cultura y postmodernidad: cambian los tiempos, cambia el profesorado. Ediciones Morata.

Kaminsky, G. (2014). Entre la mismidad y la otredad. Publicación de Ciencias Sociales que lleva adelante la Carrera de Trabajo Social de la Facultad de Ciencias Sociales. Universidad de Buenos Aires.

Maldonado, M. (2017). La Otredad Indígena en el Panorama Sociocultural Mexicano del Siglo XX. [Tesis doctoral, Universidad de Arizona]. Repositorio institucional UA. https://repository.arizona.edu/handle/10150/625857

Mena, B. (1991). Pedagogía, sociedad y crisis educativa: un proceso a la escuela del siglo XX. Escuela Universitaria A. G. B. Ávila.

Molano, O. (2007). Identidad cultural un concepto que evoluciona. Revista opera, (7), 69-84.

Morales, G. (2012). La influencia de lo quechua en la narrativa de Arguedas: un acercamiento a sus relatos. América sin nombre, (17) 47-58. http://rua.ua.es/dspace/handle/10045/26467

Porras, R. (1999). El legado quechua: indagaciones peruanas. Universidad Nacional Mayor de San Marcos.

Sánchez, H., y Reyes, C. (2009). Metodología de la Investigación y Diseños en la Investigación Científica. Lima, Perú: Visión Universitaria.

Segura, A. (2014). Reconstrucción de la memoria histórica del territorio indígena Muisca de Cota [Tesis de pregrado, Universidad Pedagógica Nacional]. Repositorio institucional UPN. http://repository.pedagogica.edu.co/handle/20.500.12209/2556

Tito, F. (2005). Sunchu: el huayno en la formación de la identidad en los migrantes quechua-hablantes de Huaycán. PROEB Andes.

Contribución de los autores

JGCA: Conceptualización, metodología, investigación, validación, redacción: revisión y edición.

AÑA: Conceptualización, metodología, investigación, validación, redacción: borrador original.

RIAO: Conceptualización, metodología, investigación, validación, redacción: borrador original.

\section{Fuentes de financiamiento}

La investigación fue realizada con recursos propios.

Conflictos de interés

No presenta conflicto de intereses. 